Check for updates

Cite this: J. Mater. Chem. C, 2017, 5,6601

Received 28th March 2017,

Accepted 30th May 2017

DOI: $10.1039 / \mathrm{c} 7 \mathrm{tc0} 01320 \mathrm{e}$

rsc.li/materials-c

\title{
A DFT study and experimental evidence of the sonication-induced cleavage of molybdenum sulfide $\mathrm{Mo}_{2} \mathrm{~S}_{3}$ in liquids $\dagger$
}

\author{
Mariia N. Kozlova, (D)*a Andrey N. Enyashin, (D) ${ }^{b}$ Ekaterina D. Grayfer, (D) ${ }^{a}$

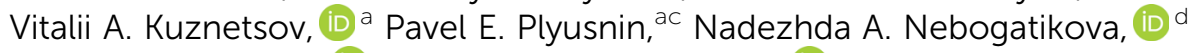 \\ Vladimir I. Zaikovskii (D) ${ }^{\text {ce }}$ and Vladimir E. Fedorov (D) *ac
}

\begin{abstract}
The Mo-S phase diagram exhibits two stable compounds: well-recognized layered molybdenum disulfide $\mathrm{MoS}_{2}$ and less studied molybdenum sesquisulfide $\mathrm{Mo}_{2} \mathrm{~S}_{3}$. Here, we build a theoretical framework for the exfoliation of $\mathrm{MO}_{2} \mathrm{~S}_{3}$ based on density functional theory calculations and further experimentally prove its dispersibility under ultrasonic treatment and demonstrate its potential for use in gas detectors. First, we report computational studies of both $\mathrm{Mo}_{2} \mathrm{~S}_{3}$ exfoliation and molecular adsorption on the $\mathrm{Mo}_{2} \mathrm{~S}_{3}$ surface. The calculations reveal the preferential direction for the fragmentation of the $\mathrm{Mo}_{2} \mathrm{~S}_{3}$ crystal along the (101) plane and, likely, chemisorptive interaction of solvent molecules, such as $\mathrm{H}_{2} \mathrm{O}$ or DMSO, with the (1)01) $\mathrm{MO}_{2} \mathrm{~S}_{3}$ surface. Next, we experimentally study the sonication of bulk $\mathrm{Mo}_{2} \mathrm{~S}_{3}$ samples in organic solvents and show that, indeed, they may be converted to colloidal nanosized sheets. Solid particles in the dispersions retain the initial $\mathrm{MO}_{2} \mathrm{~S}_{3}$ crystal structure and have the shape of plates with typical thicknesses of 5-30 nm and lateral sizes of 100-400 nm. Finally, we investigate the gas sensing properties of the $\mathrm{Mo}_{2} \mathrm{~S}_{3}$ films deposited from the dispersions towards moisture gas and several representative volatile organic compounds.
\end{abstract}

\section{Introduction}

The discovery of the unique graphene properties ${ }^{1}$ has triggered significant growth in research on nanosheets, nanoribbons and nanorods of other layered or chain-structured inorganic compounds. In particular, nanosized counterparts of hexagonal boron nitride, transition metal dichalcogenides, trichalcogenides and tetrachalcogenides ${ }^{2-8}$ have been the focus of intense research. The structures of all these compounds are characterized by weak van der Waals bonding between covalently assembled layers (or chains), allowing the exfoliation of the compounds to give nanosheets as thin as a single layer. One of the most simple

\footnotetext{
${ }^{a}$ Nikolaev Institute of Inorganic Chemistry, Siberian Branch of the Russian Academy of Sciences, 3, Acad. Lavrentiev prospect, Novosibirsk, 630090, Russian Federation. E-mail: kozlova@niic.nsc.ru, fed@niic.nsc.ru

${ }^{b}$ Institute of Solid State Chemistry, Ural Branch of the Russian Academy of Sciences, 91, Pervomayskaya st., Ekaterinburg, 620990, Russian Federation ${ }^{c}$ Novosibirsk State University, 2, Pirogova st., Novosibirsk, 630090, Russian Federation

${ }^{d}$ Rzhanov Institute of Semiconductor Physics, Siberian Branch of the Russian Academy of Sciences, 13, Acad. Lavrentiev prospect, Novosibirsk, 630090, Russian Federation

${ }^{e}$ Boreskov Institute of Catalysis, Siberian Branch of the Russian Academy of Sciences, 5, Acad. Lavrentiev prospect, Novosibirsk, 630090, Russian Federation

$\dagger$ Electronic supplementary information (ESI) available. See DOI: 10.1039/c7tc01320e
}

and effective methods to achieve this is through ultrasonic treatment of the layered material in a suitable liquid medium. This strategy is also referred to as liquid phase exfoliation. ${ }^{2,4,9}$

Molybdenum disulfide $2 \mathrm{H}-\mathrm{MoS}_{2}$ and its analogues $\left(\mathrm{MoSe}_{2}\right.$, $\mathrm{WS}_{2}, \mathrm{WSe}_{2}$, etc.) are among the compounds whose ability to form colloidal dispersions in polar organic media by ultrasound treatment is most widely studied. ${ }^{9}$ The $\mathrm{MoS}_{2}$ crystal structure (Fig. 1(a)) is composed of three-atom-thick layers S-Mo-S, oriented across and interacting weakly. As shown in numerous studies focusing on ultrasonic exfoliation, bulk $\mathrm{MoS}_{2}$ samples can be easily transferred to the nanostate, and the resulting molybdenum disulfide nanosheets show interesting catalytic, ${ }^{10}$ electrochemical, ${ }^{11,12}$ thermoelectric, ${ }^{2,13}$ luminescent $^{14,15}$ and gas sensing ${ }^{16-20}$ properties.

At the same time, there are other interesting and less studied compounds in the transition metal chalcogenide family. One such example is molybdenum sesquisulfide $\mathrm{Mo}_{2} \mathrm{~S}_{3}{ }^{21-25}$ Bulk $\mathrm{Mo}_{2} \mathrm{~S}_{3}$ shows unusual electron transport properties at low temperatures due to the metal cluster formation, ${ }^{26-30}$ and it has been suggested for use as an element for memory devices. ${ }^{31}$ More recently, $\mathrm{Mo}_{2} \mathrm{~S}_{3}$ was investigated as a cathode material. ${ }^{32}$ This compound has a complicated quasi-layered crystal structure (Fig. 1(b)) and comprises two crystallographically independent metal chains with short Mo-Mo distances extending in the 
(a)
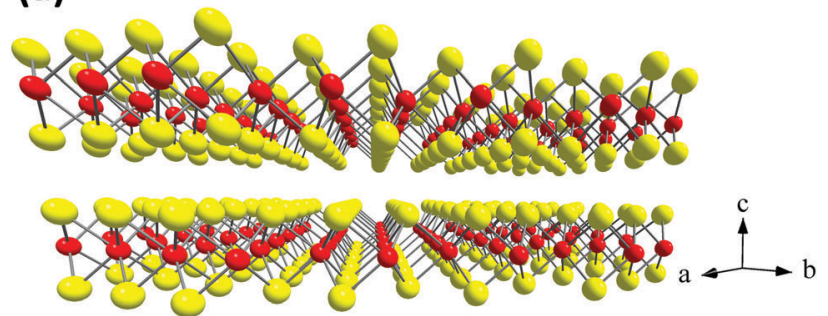

(b)

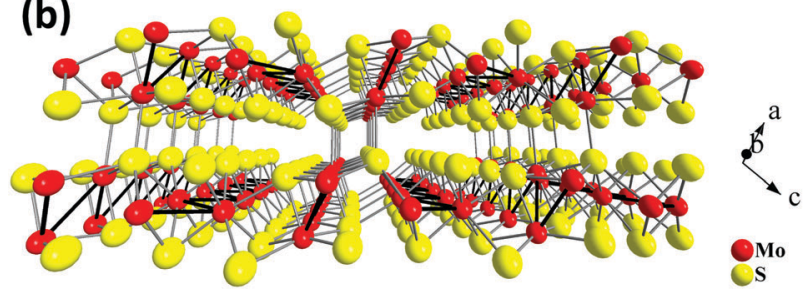

Fig. 1 Crystal structures of two stable Mo-S compounds: layered $\mathrm{MoS}_{2}$ (a) and quasi-layered $\mathrm{Mo}_{2} \mathrm{~S}_{3}$ (b).

direction of the $b$ axis (Fig. 1(b)). The comparison of the lattices of $\mathrm{Mo}_{2} \mathrm{~S}_{3}$ and $\mathrm{MoS}_{2}$ reveals that in the former, two types of bonding between layers are realized, namely, (i) weak van der Waals S . . S interactions and (ii) covalent bonds between the molybdenum atoms belonging to one layer and the sulfur atoms of the neighboring layer (Fig. 1(b), 2(c) and Fig. S1(c), ESI $\dagger$ ). On the other hand, the same structure may be imagined as a stack of molecular $1 \mathrm{~T}-\mathrm{MoS}_{2}$ layers intercalated by molecular MoS
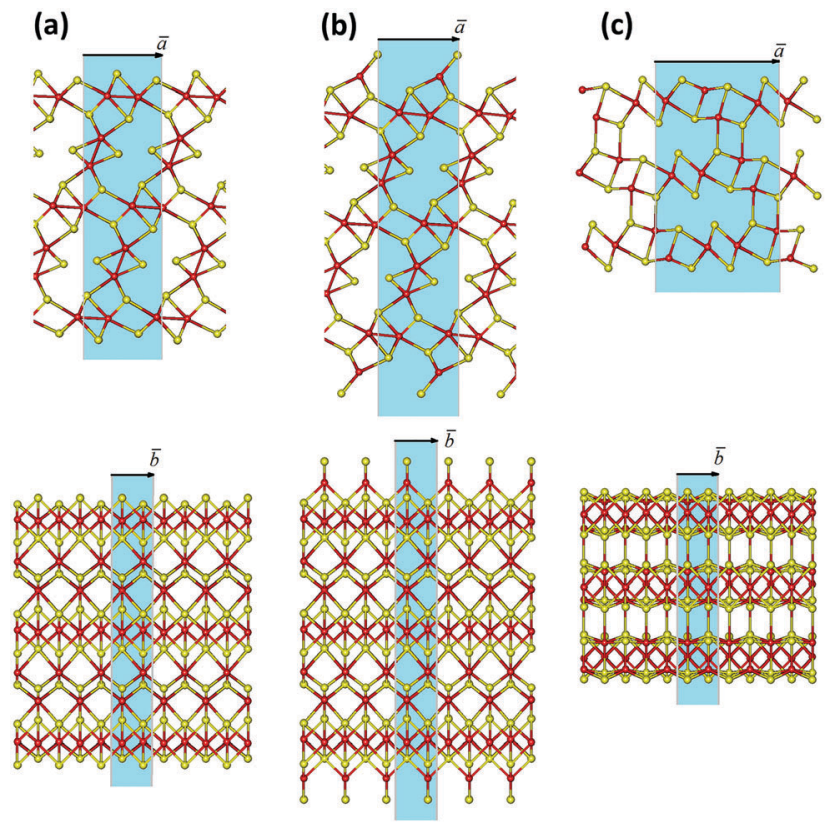

Fig. 2 Three possible methods of cleaving the $\mathrm{Mo}_{2} \mathrm{~S}_{3}$ crystal into nanosheets: (a) along the (001) plane with the removal of unsaturated Mo and $S$ atoms; (b) along the (001) plane and with tetrahedral coordination of surface Mo atoms; (c) along the (101) plane. The unit cells of the model nanosheets are highlighted in blue. Mo and $\mathrm{S}$ atoms are painted in red and yellow, respectively. The geometry of all structures is optimized using the DFT method. nanowires (Fig. 1(b), 2(a), (b), Fig. S1(a) and (b), ESI $\dagger$ ). Therefore, $\mathrm{Mo}_{2} \mathrm{~S}_{3}$ can be described as a quasi-layered structure, in contrast to the true layered $\mathrm{MoS}_{2}$, where the neighboring layers are held together only by weak van der Waals interactions. Recently, some molybdenum sesquisulfide nanomaterials were prepared with the morphology of flowers, ${ }^{33}$ nanorods, ${ }^{34}$ and thin layers. ${ }^{35-37}$ These $\mathrm{Mo}_{2} \mathrm{~S}_{3}$ nanomaterials were obtained either via hightemperature solid state reactions of $\mathrm{MoO}_{3}$ with $\mathrm{H}_{2} \mathrm{~S}^{34}$ or $\mathrm{S},{ }^{33}$ or via thermal decomposition of $\mathrm{MoS}_{2}{ }^{35,37}$ or $\operatorname{MoS}_{3} \cdot{ }^{36}$ However, $\mathrm{Mo}_{2} \mathrm{~S}_{3}$ and, especially its nanostructures, still remain relatively little studied. In particular, there is no information available on the top-down wet chemical preparation of $\mathrm{Mo}_{2} \mathrm{~S}_{3}$ nanostructures, while, as with other nanomaterials, solution processability would be an important step for testing it in potential practical applications. Also, first-principles calculations widely employed to investigate the dynamic stability and electronic structures of $2 \mathrm{D}$ materials ${ }^{38,39}$ have not been performed for $\mathrm{Mo}_{2} \mathrm{~S}_{3}$ so far.

In the present work, we use density functional theory calculations to prove the possibility of cleaving $\mathrm{Mo}_{2} \mathrm{~S}_{3}$ crystals into sheet-like fragments. The theoretical results are supported by experimental studies of $\mathrm{Mo}_{2} \mathrm{~S}_{3}$ dispersion in various liquids through ultrasonication. Finally, we demonstrate the potential of $\mathrm{Mo}_{2} \mathrm{~S}_{3}$ films prepared from the colloids as sensors for humidity and several volatile organic compounds.

\section{Experimental}

\section{Computational details}

Apart from the pristine $\mathrm{Mo}_{2} \mathrm{~S}_{3}$ bulk crystal (space group $P 2_{1} / m$ ), two-dimensional nanosheets of nanometer thickness are adopted as the basic models for the theoretical study of possible ways to cut a $\mathrm{Mo}_{2} \mathrm{~S}_{3}$ crystal. The nanosheets are designed as 1-5 molecular layers cleaved along either (001) or (101) planes of the $\mathrm{Mo}_{2} \mathrm{~S}_{3}$ crystal, whose unit cells consist of 10 to 50 atoms (Fig. 2, for more details see ESI, $\dagger$ Fig. S1). In addition, their possible surface complexes are considered using the models of $\mathrm{Mo}_{2} \mathrm{~S}_{3}(\overline{1} 01)$ five-layer nanosheets with adsorbed DMSO or water molecules.

All quantum-chemical calculations of the crystallographic and electronic properties of bulk and few-layered $\mathrm{Mo}_{2} \mathrm{~S}_{3}$ were performed within the framework of DFT using the SIESTA 4.0 package. ${ }^{40}$ The exchange-correlation potential within the generalized gradient approximation (GGA) with the Perdew-BurkeErnzerhof parametrization was used. The core electrons were treated within the frozen core approximation, applying normconserving Troullier-Martins pseudopotentials. The valence electrons were taken as $4 \mathrm{~d}^{5} 5 \mathrm{~s}^{1} 5 \mathrm{p}^{0}$ for Mo, $3 \mathrm{~s}^{2} 3 \mathrm{p}^{4} 3 \mathrm{~d}^{0}$ for $\mathrm{S}$, $2 \mathrm{~s}^{2} 2 \mathrm{p}^{4}$ for $\mathrm{O}, 2 \mathrm{~s}^{2} 2 \mathrm{p}^{2}$ for $\mathrm{C}$ and $1 \mathrm{~s}^{1}$ for $\mathrm{H}$. The pseudopotential core radii were chosen as $2.43 \mathrm{a}_{\mathrm{B}}$ for Mo4d and Mo5s, $2.62 \mathrm{a}_{\mathrm{B}}$ for Mo5p states, and 1.69, 1.45, 1.20 and $0.15 \mathrm{a}_{\mathrm{B}}$ for all S, O, $\mathrm{C}$ and $\mathrm{H}$ states, respectively. In all calculations, a double- $\zeta$ polarized basis set was used. The $k$-point mesh was generated by the Monkhorst-Pack method. For $k$-point sampling, a cutoff of $10 \AA$ was used. The real-space grid used for numeric integrations was set to correspond to the energy cutoff of $300 \mathrm{Ry}$. 
The calculations of pristine $\mathrm{Mo}_{2} \mathrm{~S}_{3}$ structures were performed using variable-cell and atomic position relaxations, with convergence criteria corresponding to the maximum residual stress of $0.1 \mathrm{GPa}$ for each component of the stress tensor, and the maximum residual force component of $0.05 \mathrm{eV} \AA^{-1}$. In the calculations of two-dimensional adsorption complexes, only the atomic position relaxation was employed, while the lattice parameters were kept as those optimized for clean $\mathrm{Mo}_{2} \mathrm{~S}_{3}$ nanosheets. For all two-dimensional structures, the out-plane lattice parameter was equal to $50 \AA$ to avoid a spurious interaction with the periodic image.

\section{Synthesis of bulk $\mathrm{Mo}_{2} \mathrm{~S}_{3}$}

The polycrystalline $\mathrm{Mo}_{2} \mathrm{~S}_{3}$ samples were obtained by a hightemperature $\left(1150{ }^{\circ} \mathrm{C}\right)$ reaction of equivalent $\mathrm{MoS}_{2}$ and Mo amounts in an evacuated and sealed quartz ampoule. ${ }^{29}$

\section{Preparation of colloidal dispersions}

Fine powder of $\mathrm{Mo}_{2} \mathrm{~S}_{3}(50 \mathrm{mg})$ was mixed with a solvent $(30 \mathrm{~mL})$ in a glass vial and ultrasonicated in a "Sapphire" ultrasound bath (ultrasound power $150 \mathrm{~W}$, frequency $35 \mathrm{kHz}$ ) during $4 \mathrm{~h}$. Large particles were settled down for $16 \mathrm{~h}$. The upper parts of mixtures were isolated and investigated by a set of methods. Following this procedure, water, ethanol, an ethanol-water mixture (vol. ratio of $1: 1$ ), isopropanol (i-PrOH), acetonitrile, dimethylformamide (DMF), dimethyl sulfoxide (DMSO), and $\mathrm{N}$-methyl-2-pyrrolidone (NMP) were tested as dispersive media. Solid particles in the form of films were separated from the colloidal dispersions by filtration of the dispersions through the membrane filters with pore size $0.02 \mu \mathrm{m}$ (Whatman, Anodisc 25). The films were washed with ethanol and dried under mild vacuum at $70{ }^{\circ} \mathrm{C}$ for $1 \mathrm{~h}$.

\section{Characterization}

X-ray powder diffraction (XRPD) patterns for solid samples (powders and films) were collected using a Philips PW 1830/1710 automated diffractometer $\left(\mathrm{Cu} \mathrm{K}_{\alpha}\right.$ radiation, graphite monochromator, silicon plate as an external standard). Zeta-potentials and dynamic light scattering (DLS) spectra were measured by using ZetaSizer Nano-ZS equipment. The thickness of the particles and surface morphology were evaluated by using a scanning probe microscope (Solver P-47H, NT-MDT, Russia). Images were obtained in atomic force microscopy (AFM) mode using non-contact cantilevers (NSG-11, NT-MDT, Russia). The samples were prepared using several drops of diluted colloidal dispersions in an ethanol-water mixture (vol. ratio of $1: 1$ ), which were applied to mica pieces, and dried at $70{ }^{\circ} \mathrm{C}$ for $2 \mathrm{~h}$. High-resolution transmission electron microscopy (HRTEM) images were obtained by using a JEM-2010 (JEOL Ltd.) microscope with a lattice-fringe resolution of $0.14 \mathrm{~nm}$ at an accelerating voltage of $200 \mathrm{kV}$. Suspensions in the ethanol-water mixture were deposited on carbon film-coated copper grids. The lattice spacing was calculated by fast Fourier transform (FFT) using DigMicrograph (GATAN) software. Energy dispersive X-ray spectroscopy (EDS) was performed on a Hitachi TM3000 TableTop SEM equipped with Bruker QUANTAX 70
EDS equipment. Thermogravimetric analyses (TGA) were carried out on a TG 209 F1 Iris thermobalance (NETZSCH, Germany). The measurements were performed in a helium flow in the temperature range of $30-900{ }^{\circ} \mathrm{C}$ using a heating rate of $10{ }^{\circ} \mathrm{C} \mathrm{min}{ }^{-1}$, a gas flow rate of $60 \mathrm{~mL} \min ^{-1}$ and open $\mathrm{Al}_{2} \mathrm{O}_{3}$ crucibles. The simultaneous TG-DSC/EGA-MS measurement was performed in an apparatus consisting of a STA 449 F1 Jupiter thermal analyzer and a QMS 403D Aëolos quadrupole mass spectrometer (NETZSCH, Germany). The spectrometer was connected online to a thermal analyzer (STA) instrument by a quartz capillary heated to $280{ }^{\circ} \mathrm{C}$. The QMS was operated with an electron impact ionizer with an energy of $70 \mathrm{eV}$. The ion currents of the selected mass/charge $(\mathrm{m} / \mathrm{z})$ numbers were monitored in multiple ion detection (MID) mode with a collection time of $1 \mathrm{~s}$ for each channel. The measurements were performed in a helium flow in the temperature range of $30-500{ }^{\circ} \mathrm{C}$ using a heating rate of $10{ }^{\circ} \mathrm{C} \mathrm{min}{ }^{-1}$, a gas flow rate of $30 \mathrm{~mL} \mathrm{~min}{ }^{-1}$ and open $\mathrm{Al}_{2} \mathrm{O}_{3}$ crucibles.

\section{Formation and measurements of a vapor sensing element based on $\mathrm{Mo}_{2} \mathrm{~S}_{3}$ nanosheets}

A thin film assembled from $\mathrm{Mo}_{2} \mathrm{~S}_{3}$ colloidal dispersions was used for measurements. The experimental sample was formed by cutting the filtered film. Electrical contacts were made of graphite paste and lead thin copper wires. Electrical resistance of the sample was measured by a standard four-point probe method, with the dc voltage being measured using a Keithley 2000. Vapor-induced changes in the resistance of the experimental sample under room conditions (relative humidity in the laboratory was $12 \%$ ) were monitored using a glass chamber 8.7 L in volume. A certain volume of $\mathrm{H}_{2} \mathrm{O}$, DMSO, ethanol or acetone was evaporated inside the chamber, with $\mathrm{H}_{2} \mathrm{O}$ and DMSO being coated onto filter paper for better evaporation. Once thermodynamic equilibrium was reached, the air-dried $\mathrm{Mo}_{2} \mathrm{~S}_{3}$ sample was placed into the chamber, and the resistance change was registered. After the sample was exposed, it was taken out of the chamber back into room conditions, and resistance relaxation was recorded. The experiment was repeated with varying volumes of water, DMSO, ethanol and acetone.

\section{Results and discussion}

\section{DFT calculations of the bulk $\mathrm{Mo}_{2} \mathrm{~S}_{3}$}

In order to understand whether free-standing few-layered $\mathrm{Mo}_{2} \mathrm{~S}_{3}$ nanosheets are energetically favorable and/or can be stabilized by adsorbing solvent molecules, DFT calculations have been carried out. As a starting point, the bulk crystal of $\mathrm{Mo}_{2} \mathrm{~S}_{3}$ was studied. The lattice parameters of the bulk $\mathrm{Mo}_{2} \mathrm{~S}_{3}$ after geometry optimization have been found to be $a=6.219 \AA, b=3.232 \AA, c=8.742 \AA$, and $\beta=102.67^{\circ}$, which are in fair agreement with experimental data $\left(a=6.092 \AA, b=3.208 \AA, c=8.633 \AA\right.$, and $\left.\beta=102.43^{\circ}\right) .{ }^{31,41}$ All Mo atoms have a distorted octahedral coordination by $\mathrm{S}$ atoms, and the Mo-S bond lengths vary from 2.37 to $2.60 \AA$ A. A zigzag-like ordering of Mo atoms along the [010] direction and within the (001) and (101) planes can be distinguished. The average Mo-Mo 

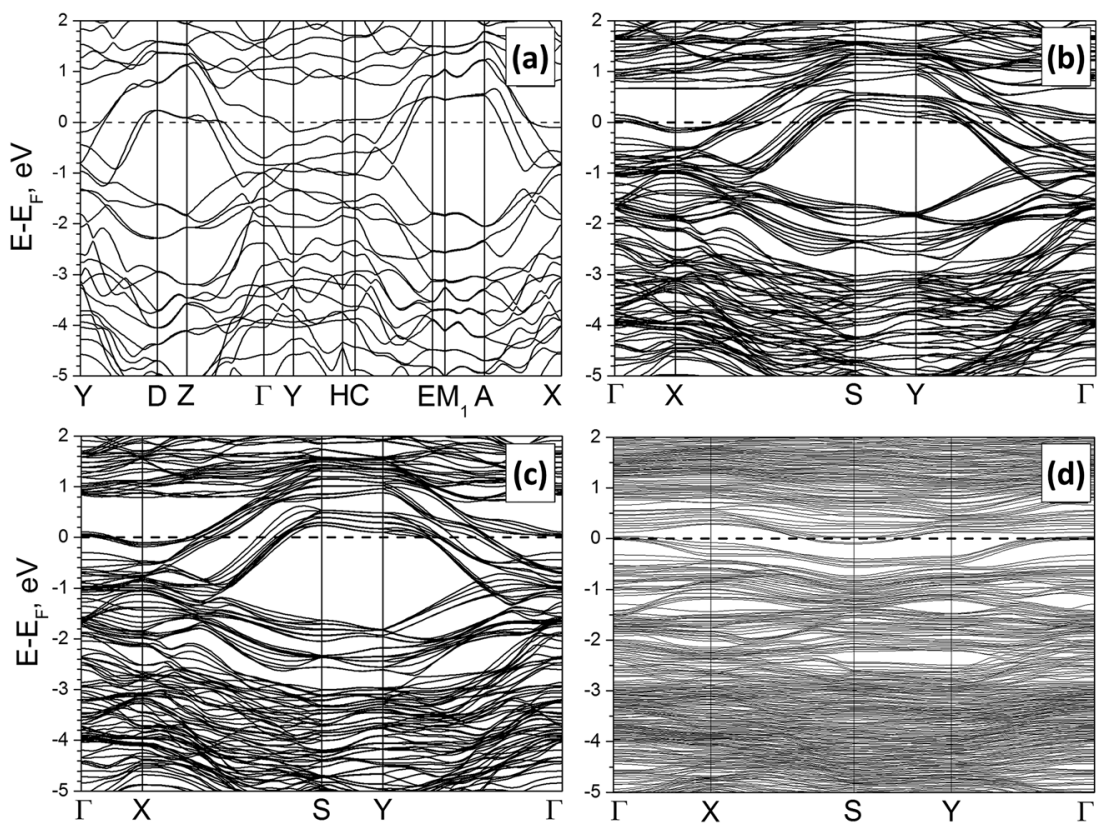

Fig. 3 Band structures of the bulk $\mathrm{MO}_{2} \mathrm{~S}_{3}$ (a), a clean $\mathrm{MO}_{2} \mathrm{~S}_{3}(\overline{10})$ five-layer nanosheet (b) and the same nanosheet with $\mathrm{H}_{2} \mathrm{O}$ (c) or DMSO molecules (d) anchored to Mo atoms. DFT calculations.

distances are equal to $2.89 \AA$ and $2.83 \AA$, which are comparable with the Mo-S bond lengths and suggest the presence of covalent-type Mo-Mo bonding. The latter is confirmed by analysis of the electronic structure.

The calculated band structure and density of electronic states (DOS) for crystalline $\mathrm{Mo}_{2} \mathrm{~S}_{3}$ are depicted in Fig. 3(a) and Fig. S2(A) (ESI $\dagger)$. The compound possesses a metal-like character with the Fermi level hosted at the local DOS minimum. Two main groups of states within the valence band can be outlined, accordingly to the different types of chemical bonding. The first group at -7 to $-2 \mathrm{eV}$ is formed by a mixture of S3p- and Mo4d-states, which are responsible for covalent Mo-S bonding. The second group is closer to the Fermi level and is presented mainly by Mo4d-states, providing covalent Mo-Mo bonding and -Mo-Mo- chain formation along the [010] direction.

The values of crystal orbital overlap population (COOP) also evidence Mo-Mo bonding. Particularly, COOPs between the nearest neighbor Mo atoms within the (001) and (101) planes are equal to $0.078 e$ and $0.090 e$, respectively, while those between the second neighbor Mo atoms are equal to $0.042 e$ and $0.040 e$. COOPs for the most of the Mo-S bonds within distorted $\mathrm{MoS}_{6}$ octahedra have values around 0.23-0.26 e. Yet, Mo-S bonds at the boundaries of cross-sections like those drawn in Fig. S1(A) and (C) (ESI $\dagger$ ) have lower COOPs of 0.17 and $0.19 e$, respectively, and might be the weakest links. Therefore, preferential cleavage or exfoliation of the crystal might be expected along the (001) or (101) planes. This preliminary guess can be proven after the direct calculations of the formation energies for the few-layered sheets.

\section{DFT calculations of few-layered $\mathrm{Mo}_{2} \mathrm{~S}_{3}$ nanosheets}

There may exist different directions to cleave a $\mathrm{Mo}_{2} \mathrm{~S}_{3}$ crystal, and the choice may be made intuitively (Fig. 2 and Fig. S1, ESI†).
The cleavages of $\mathbf{a}$ or $\mathbf{b}$ type disclose a stratiform structure of the $\mathrm{Mo}_{2} \mathrm{~S}_{3}$ crystal as a stack of molecular 1T-MoS $\mathrm{S}_{2}$ layers intercalated by molecular MoS nanowires. The nanosheets of $a$ type have an octahedral coordination of all Mo atoms and a sulfur-rich composition approaching $\mathrm{Mo}_{2} \mathrm{~S}_{3}$ with the thickness growth. The strictly stoichiometric nanosheets of $\mathbf{b}$ type should have a tetrahedral coordination of surface Mo atoms. In contrast, the cleavage of $\mathbf{c}$ type in Fig. 2 and Fig. S1 (ESI $\dagger$ ) leads to nanosheets of both unperturbed stoichiometry and Mo coordination.

The initial bond lengths and valence angles within models of all $\mathrm{Mo}_{2} \mathrm{~S}_{3}$ nanosheets corresponded to the ones of the bulk. The vectors along the [100] or [101] directions in the crystal were chosen as the main translation vectors $\bar{a}$ for nanosheets of types a or $\mathbf{b}$ and $\mathbf{c}$, respectively (Fig. 2 and Fig. S1, ESI $\dagger$ ), while the translational vector $\bar{b}$ for all nanosheets corresponded to $\bar{b}$ in the crystal. Geometry optimization of 2D nanostructures reveals their slight in-plane contraction depending on the thickness, and a predominant decrease of the lattice parameter $a$, e.g., stoichiometric nanosheets (Fig. 2(b) (Fig. S1(b), ESI $†$ ) and Fig. 2(c) (Fig. S1(c), ESI $\dagger$ )) with thicknesses of 1 and 5 layers undergo contractions of $2 \%$ and $0.5 \%$, respectively. The structure of non-stoichiometric nanosheets (Fig. 2(a) and Fig. S1(a), $\mathrm{ESI} \dagger$ ) with the same thicknesses and compositions of $\mathrm{Mo}_{2} \mathrm{~S}_{4}$ and $\mathrm{Mo}_{2} \mathrm{~S}_{3.11}$ demonstrates contractions of $7 \%$ and $1 \%$, respectively. The change in the lattice parameter $b$ is negligible, and its value for thick nanosheets is identical to that for the crystal.

The relative stability of the nanosheets was analyzed as a function of the surface termination and thickness (Fig. 4). The nanosheets with (101) termination (type c, Fig. 2 and Fig. S1, ESI $\dagger$ ) appear to be the most stable among all considered types, independent of the nanosheet stoichiometry and thickness. The relative energies of all nanosheets decrease as the 


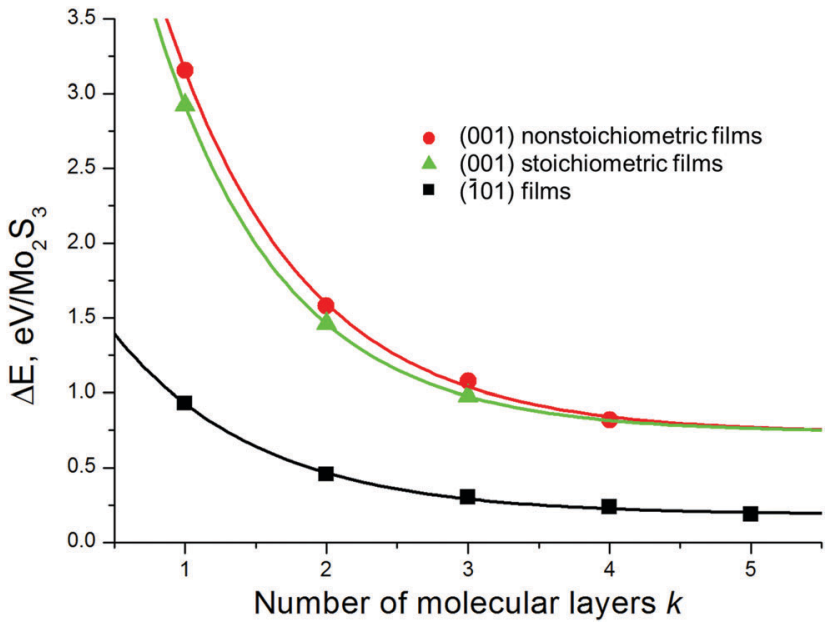

Fig. 4 Relative energy of $\mathrm{Mo}_{2} \mathrm{~S}_{3}$ nanosheets as a function of their thickness and the type of cleavage. The bulk $\mathrm{Mo}_{2} \mathrm{~S}_{3}$ crystal is chosen as the reference system. DFT calculations.

nanosheet thickness grows and rapidly converge to the values of the energies of surface formation, namely, $0.15 \mathrm{eV} \AA^{-2}$ for $\mathrm{Mo}_{2} \mathrm{~S}_{3}(\overline{101})$ and $0.73 \mathrm{eV} \AA^{-2}$ for the $\mathrm{Mo}_{2} \mathrm{~S}_{3}(001)$ surface. Noteworthy, the first value is only 5 times larger than the typical energy of van der Waals binding within layered dichalcogenides like $\mathrm{MoS}_{2}\left(\sim 0.02-0.03 \mathrm{eV} \AA^{-2}\right) .{ }^{39}$

The electronic properties of the nanosheets are regulated mostly by their type and weakly depend on the thickness. Main peculiarities in the band structure and DOS of the most stable $\mathrm{Mo}_{2} \mathrm{~S}_{3}(\overline{1} 01)$ nanosheet consisting of 5 layers are visualized in Fig. 3(b) and Fig. S2(b) (ESI $\dagger$ ). Despite the rise of the surface, the metal-like character of $\mathrm{Mo}_{2} \mathrm{~S}_{3}$ is preserved. The DOS profile and distribution of partial DOS, as well as the position of the Fermi level, are very similar to those of the bulk $\mathrm{Mo}_{2} \mathrm{~S}_{3}$. Moreover, certain parts of the band structure of the nanosheet can be correlated with the band structure of the crystal along equivalent points (namely, $\mathrm{X}-\mathrm{S}-\mathrm{Y}-\Gamma$ and $\Gamma-\mathrm{X}$ in the nanosheet $v$ s. $\mathrm{Y}-\mathrm{D}-\mathrm{Z}-\Gamma$ and $\Gamma-Y$ in the crystal). The only difference is a larger dispersion of the bands for the nanosheet due to the simultaneous presence of surface and volume atoms.

Such a great similarity between the electronic properties of $\mathrm{Mo}_{2} \mathrm{~S}_{3}$ within the bulk and within a nanosheet predicates that the intrinsic conductance of the nanosheets should not be too different from that along equivalent directions of the crystal. In addition, the partial DOS analysis of the nanosheet depending on the depth does not reveal an essential difference either in the distribution or in the intensity of Mo4d-states. Therefore, the electric conductivity of the pure surface should not be essentially different from the conductivity of the bulk.

\section{DFT calculations of $\mathrm{Mo}_{2} \mathrm{~S}_{3}$ nanosheets with $\mathrm{H}_{2} \mathrm{O}$ or DMSO adsorbates}

As our calculations prove the preferential cleavage of the fewlayered $\mathrm{Mo}_{2} \mathrm{~S}_{3}$ nanosheets along the (101) plane, in practice it would mean the possibility of their formation and stabilization under the influence of ultrasonication in an organic solvent, much similarly to the truly layered compounds, such as $\mathrm{MoS}_{2}$ or graphite. In this case, the interactions between the nanosheets and the solvent molecules would play an important role in the stabilization of the colloidal nanosheets. Earlier works employed DFT calculations to study the interactions between $\mathrm{MoS}_{2}$ nanosheets and amino acids ${ }^{42}$ or protein functional groups. ${ }^{43}$ Therefore, the study of the stability of adsorption complexes between the $\mathrm{Mo}_{2} \mathrm{~S}_{3}$ surface and solvent molecules was performed using the model of the five-layer $\mathrm{Mo}_{2} \mathrm{~S}_{3}(\overline{101})$ nanosheet and a single layer of water or DMSO molecules anchored to all Mo surface atoms. $\mathrm{H}_{2} \mathrm{O}$ molecules were considered as monodentate O-ligands, while DMSO molecules acted either as bidentate SO-ligands or monodentate O- or S-ligands. In all situations, excluding DMSO anchoring via the S-atom, the adsorption is exothermic and can be characterized as chemisorption. The calculated adsorption energies are equal to -1.32 and $-0.71 \mathrm{eV}$ for monodentate $\mathrm{H}_{2} \mathrm{O}$ and DMSO O-ligands, respectively, and $-1.60 \mathrm{eV}$ for bidentate DMSO. Endothermic adsorption of DMSO molecules as S-ligands with energy $+1.14 \mathrm{eV}$ might be explained by a sterical hindrance and a large repulsion between "lying" disc-shaped molecules. There is a small charge transfer around $0.05 e$ from adsorbed $\mathrm{H}_{2} \mathrm{O}$ or DMSO molecules to the $\mathrm{Mo}_{2} \mathrm{~S}_{3}$ part.

The coordination bond lengths within stable adsorption complexes are estimated as $2.36 \AA$ for $\mathrm{Mo}^{-\mathrm{OH}_{2}, 2.75 \AA \text { for }}$ $\mathrm{Mo} \cdots \mathrm{O}=\mathrm{S}\left(\mathrm{CH}_{3}\right)_{2}$ and $2.47 \AA$ for $\mathrm{Mo} \cdots \mathrm{S}\left(\mathrm{CH}_{3}\right)_{2}=\mathrm{O}$. No surface reconstruction is revealed after deposition of the water layer, while a slight dispersion in the values of dihedral angles within the $\mathrm{Mo}_{2} \mathrm{~S}_{3}$ part can be detected (Fig. 5).

A comparison of band structures and DOS distributions between a clean $\mathrm{Mo}_{2} \mathrm{~S}_{3}$ nanosheet and an adsorbate-modified one does not establish an essential difference. $\mathrm{Mo}_{2} \mathrm{~S}_{3}$ preserves the metal-like character even after deposition of molecules at the surface (Fig. S2(d), ESI $\dagger$ ). The most pronounced feature is the rise of new impurity levels in DOS. Adsorption of $\mathrm{H}_{2} \mathrm{O}$ leads to the rise of the strong localized $\mathrm{O} 2 \mathrm{p}$-states at $-12 \mathrm{eV}$ as well as the O2p-states partially overlapping with the bottom of the valence band at -8 and $-6 \mathrm{eV}$. Adsorption of DMSO molecules leads to a similar effect. Then, the DOS profile of the adsorption complex is characterized by $\mathrm{O} 2 \mathrm{p}$ - and $\mathrm{S} 3 \mathrm{p}$-states of the $\mathrm{S}=\mathrm{O}$ group near the bottom of the valence band and the deep states from $\mathrm{C}$ and $\mathrm{H}$ atoms.

\section{Experimental study of $\mathrm{Mo}_{2} \mathrm{~S}_{3}$ in colloids}

Further, theoretically predicted exfoliation of $\mathrm{Mo}_{2} \mathrm{~S}_{3}$ was achieved experimentally. First, the bulk polycrystalline $\mathrm{Mo}_{2} \mathrm{~S}_{3}$ was synthesized by a high-temperature reaction between $\mathrm{MoS}_{2}$ and Mo; the phase identity was confirmed by the XRPD pattern (Fig. S3, ESI $\dagger$ ). The EDS results showed the proportion of molybdenum $v s$. sulfur atoms to be $40: 59$, which is close to the theoretically calculated value of $2: 3$. Therefore, the samples obtained are the bulk singlephase $\mathrm{Mo}_{2} \mathrm{~S}_{3}$.

Next, we examined the colloidal dispersions that formed upon sonication of the bulk $\mathrm{Mo}_{2} \mathrm{~S}_{3}$ in organic media. The series of solvents appropriate for liquid phase exfoliation of $\mathrm{MoS}_{2}$ was tested for $\mathrm{Mo}_{2} \mathrm{~S}_{3}$. The resulting dispersions have a grey color 


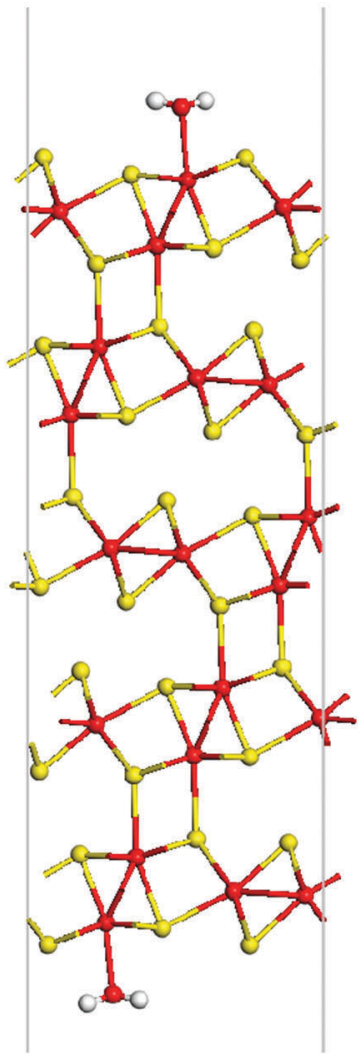

(a) (b)

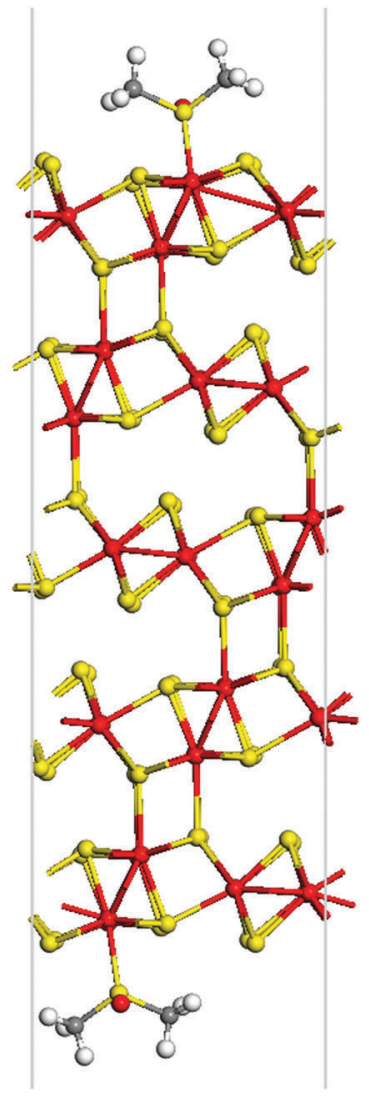

Fig. 5 Unit cells of the adsorption complex of a $\mathrm{MO}_{2} \mathrm{~S}_{3}(\overline{1} 01)$ five-layer nanosheet and monodentate $\mathrm{H}_{2} \mathrm{O}$ (a) or bidentate DMSO molecules (b) viewed along the [010] direction. The $\mathrm{S}=\mathrm{O}$ bonds of DMSO molecules are aligned along the [010] direction. The geometry of both structures is optimized using the DFT method.

and exhibit the Tyndall effect, showing the presence of colloidal particles in the liquid media (Fig. 6(a)). The average hydrodynamic particle size in dispersions was determined by DLS to be $190 \mathrm{~nm}$ with a deviation of $90 \mathrm{~nm}$ (Fig. 6(b)). The concentrations $\left(\mathrm{mg} \mathrm{L}^{-1}\right)$ of dispersions in different solvents estimated by the weight method are as follows: water $(<20)$, ethanol $(30)$, ethanol-water mixture (vol. ratio of $1: 1$ ) (70), i-PrOH (50), acetonitrile (30), DMF (0), and NMP (70). One can see that, similarly to $\mathrm{MoS}_{2}, \mathrm{Mo}_{2} \mathrm{~S}_{3}$ is well dispersed in NMP and an alcohol/water mixture, however, the highest concentration of $130 \mathrm{mg} \mathrm{L}^{-1}$ is found for the $\mathrm{Mo}_{2} \mathrm{~S}_{3} / \mathrm{DMSO}$ dispersion. The zeta-potentials were measured for colloidal dispersions in the ethanol-water mixture to be about -35 to $-40 \mathrm{mV}$, confirming the good stability of the colloids.

For establishing the morphology of the particles in dispersions, detailed HRTEM and AFM studies have been carried out. HRTEM data (Fig. 7(a), (b) and Fig. S4, ESI $\dagger$ ) show that the dispersions contain "crumpled" plate-shaped particles of few hundred nanometers in lateral size. The plate thickness varies from $5 \mathrm{~nm}$ to $30 \mathrm{~nm}$. Fig. 7(b) shows the HRTEM image of a $\sim 15 \mathrm{~nm}$ thick plate, with the interplanar spacing being $0.55 \mathrm{~nm}$, that corresponds to the (101) plane. The FFT image in the inset of Fig. 7(b) displays a row of reflections corresponding to the lattice spacing of $d_{-101}=0.5498 \mathrm{~nm}$. The HRTEM image corresponding to the zone axis [101] was simulated by using Stadelmann's software ${ }^{44}$ and was found in good agreement with the experimental image (see Fig. S5, ESI $\dagger$ ). According to the AFM study, particles have the shape of the plates with typical lateral dimensions of 100-400 $\mathrm{nm}$ and thicknesses of 8-50 nm. The particle visualized in Fig. 7(c) is the particle that consists of two closely placed particles of about $250 \mathrm{~nm}$ in size, and 8-20 nm in thickness (see the profile in Fig. 7(d)). According to the XRPD study (Fig. S6, ESI $\dagger$ ), solid particles retain the initial $\mathrm{Mo}_{2} \mathrm{~S}_{3}$ identity independent of the type of solvent.

Therefore, it is clearly shown that the bulk quasi-layered $\mathrm{Mo}_{2} \mathrm{~S}_{3}$ can be successfully dispersed by sonication in various liquid media. The particles in colloids mostly adopt a nanosheetlike morphology that proves the existence of a preferential direction for their exfoliation. This finding is in good agreement with the results of DFT calculations presented in the previous part and with earlier findings on the exfoliation of layered $\mathrm{MoS}_{2}$. Powerful sonication is known to break both the weak van der Waals bonds and the stronger covalent bonds, thus cutting $\mathrm{MoS}_{2}$ or graphene into smaller sheets. ${ }^{45,46}$ Apparently, in our case of $\mathrm{Mo}_{2} \mathrm{~S}_{3}$, Mo-S bonds between adjacent "layers" (or within them) could be overcome as well. The effectiveness of certain solvents in the stabilization of colloidal nanosheets is often explained in terms of solution thermodynamics. It is argued that successful solvents for many layered materials $\left(\mathrm{MoS}_{2}, \mathrm{~h}-\mathrm{BN}\right.$, graphite, etc.) should have surface energies close (a)

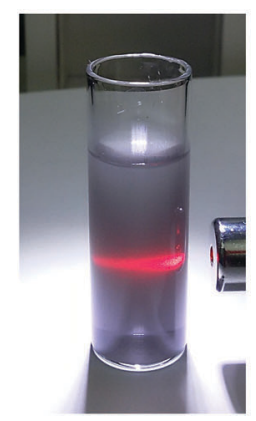

(b)

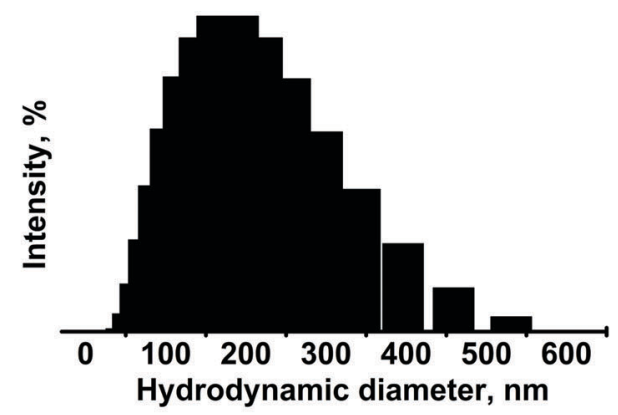

Fig. 6 (a) Photograph of the $\mathrm{Mo}_{2} \mathrm{~S}_{3}$ dispersion in an ethanol-water mixture (vol. ratio of 1:1) exhibiting the Tyndall effect. (b) DLS data for the Mo $\mathrm{S}_{3}$ dispersion in the ethanol-water mixture (vol. ratio of $1: 1$ ). The mean hydrodynamic particle size is $190 \mathrm{~nm}$ with a deviation of $90 \mathrm{~nm}$. 

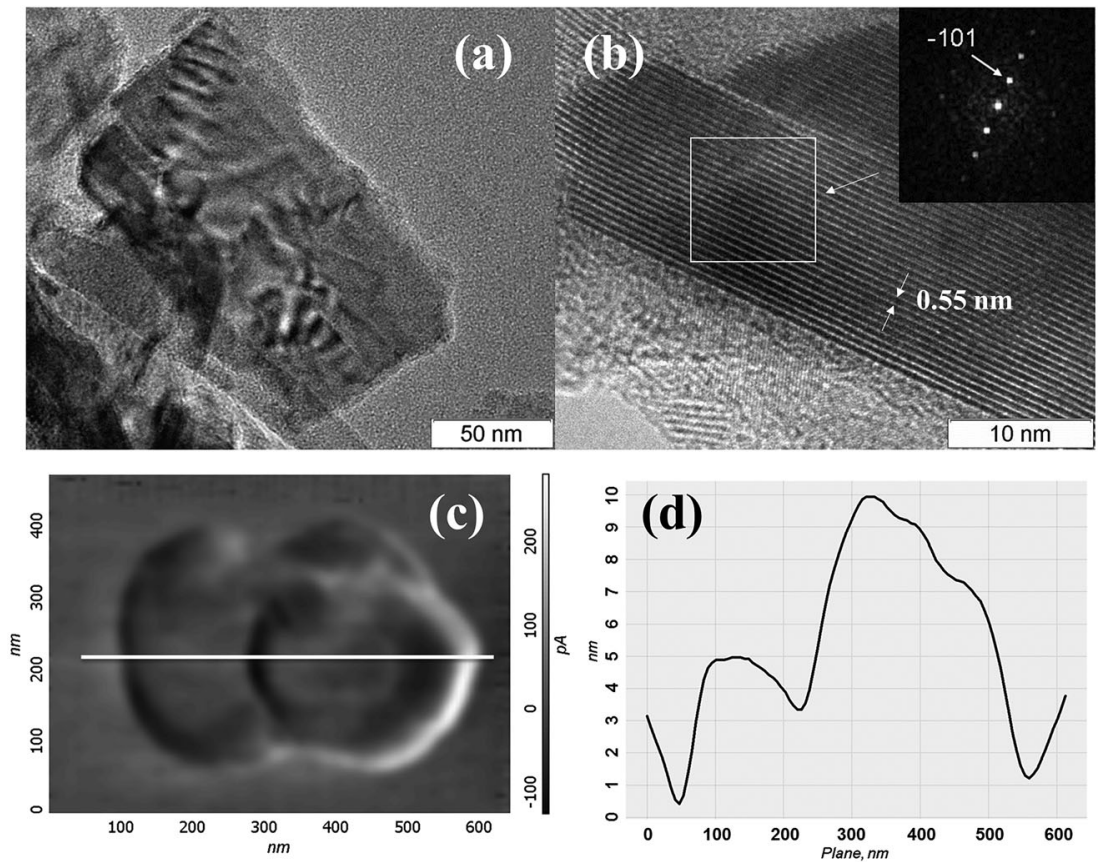

Fig. 7 HRTEM images of $\mathrm{MO}_{2} \mathrm{~S}_{3}$ from the ethanol-water dispersion; (a) and (b) close views of a $\mathrm{MO}_{2} \mathrm{~S}_{3}$ nanosheet as seen from the top and side, respectively; the inset is the FFT pattern from a selected area; (c) AFM image in lateral force mode of particles in the dispersion and (d) their AFM profile.

to those of nanosheets $\left(\sim 70 \mathrm{~mJ} \mathrm{~m}{ }^{-2}\right){ }^{2}$ Another aspect to bear in mind is the possibility of chemisorption or chemical interaction between the colloidal nanostructures and solvent molecules. ${ }^{45,47,48}$ For our colloidal $\mathrm{Mo}_{2} \mathrm{~S}_{3}$ nanosheets, this version is to some extent corroborated by the observed high negative zeta-potential. A complex of several factors is involved in the dispersion process: (i) breaking of van der Waals bonds, (ii) breaking of covalent Mo-S bonds within the layers and (iii) breaking of interlayer covalent Mo-S bonds. The latter two circumstances would lead to the creation of highly reactive molybdenum centers. Being highly chalcophilic and complex formers as they do, the under-coordinated Mo atoms at the edges and at the surfaces can be stabilized by complexing solvent molecules. In fact, the DFT calculations discussed above predict the stability of such adsorbate complexes. To check this assumption experimentally, we use TGA and mass-spectrum analyses to study $\mathrm{Mo}_{2} \mathrm{~S}_{3}$ deposited from the colloids.

\section{Thermoanalytical and mass-spectrometric analyses}

The presence of solvent molecules within the solid phase deposited from the DMSO colloidal dispersion was confirmed by simultaneous TG-DSC/EGA-MS analyses (Fig. 8). When the sample is heated up to $125{ }^{\circ} \mathrm{C}$ under an inert atmosphere, the mass loss of about $0.14 \%$ is due to the removal of adsorbed water molecules. In the mass-spectrum, a slight increase in the ion current of the particles with $\mathrm{m} / \mathrm{z}=18$ is observed (it is not shown in Fig. 8). Continuous heating up to temperatures in the interval of $125-250{ }^{\circ} \mathrm{C}$ leads to a mass loss of $0.4 \%$. This is accompanied by an increase in the ion current of the particles with $m / z=15,45,29,61,46,47$, and 48 . Such a number of fission ions indicates that DMSO molecules are the main gas

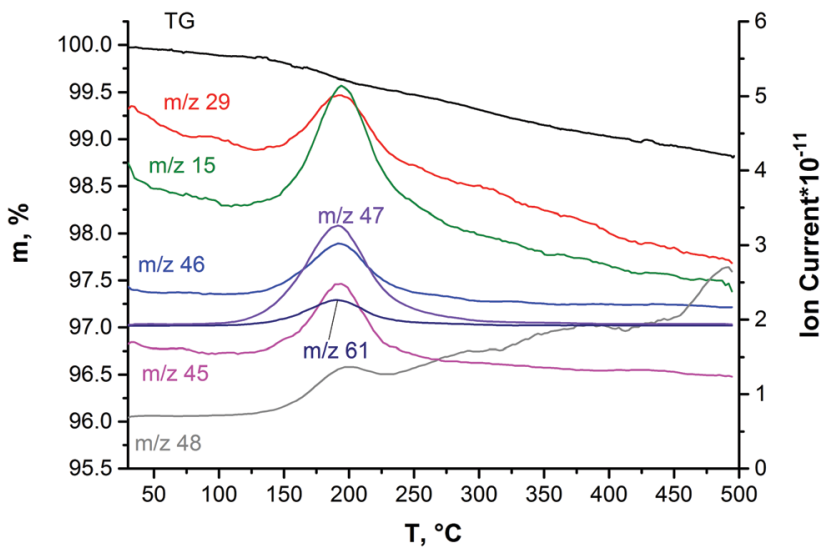

Fig. 8 The data of TG-DSC/EGA-MS obtained on $\mathrm{Mo}_{2} \mathrm{~S}_{3}$ precipitated from the colloidal dispersion in DMSO.

products evolving at this stage. This temperature interval in the inert atmosphere is in good agreement with the boiling point of pure DMSO $\left(189^{\circ} \mathrm{C}\right)$. We suggest that the absence of currents corresponding to the fission ion with $\mathrm{m} / \mathrm{z}=63$ and the molecular ion with $m / z=78$ is due to high temperature $\left(280{ }^{\circ} \mathrm{C}\right)$ in the capillary of the transport line from the STA device to the mass-spectrometer that causes thermal deconstruction of the DMSO molecules. The sum of mass losses when heated up to $850{ }^{\circ} \mathrm{C}$ is $1.8 \%$. It may be due to the removal of the products of DMSO decomposition. Therefore, it is probable that the "exposed" molybdenum atoms resulting from the rupture of Mo-S bonds during the ultrasonic treatment of $\mathrm{Mo}_{2} \mathrm{~S}_{3}$ may be stabilized by complexing solvent molecules or their residues, similarly to $\mathrm{MoS}_{2},{ }^{45,49}$ especially, taking into account the formation 

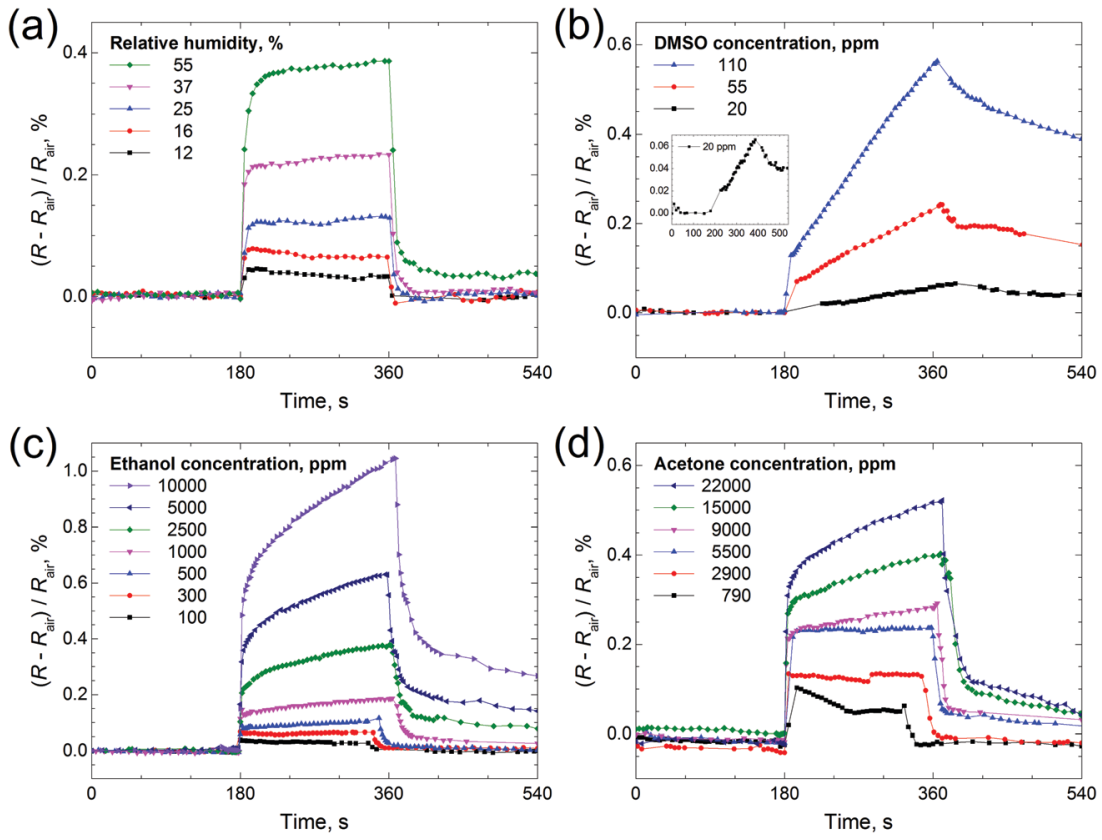

Fig. 9 Time dependence of electrical resistance of the $\mathrm{Mo}_{2} \mathrm{~S}_{3}$ thin film sample in the presence of target gases: (a) $\mathrm{H}_{2} \mathrm{O}$, (b) DMSO, (c) ethanol and (d) acetone. The inset in (b) presents an enlarged view of the response to $20 \mathrm{ppm}$ of DMSO. $R_{\text {air }}$ is the resistance of the sample under room conditions, and the relative humidity in the room was $12 \%$. Each experiment consisted of three 180 s steps: (1) the sample was kept under room conditions, (2) it was placed inside a glass chamber with the vapors and (3) it was taken out of the chamber back into room conditions.

of many active species through solvent sonolysis. ${ }^{4,47,48}$ In previous works, the $\mathrm{Mo}_{2} \mathrm{~S}_{3}$ surface was also shown to have high affinity for some organic molecules, such as anthraquinones. ${ }^{35}$

\section{Sensing properties of the $\mathrm{Mo}_{2} \mathrm{~S}_{3}$ thin film toward vapors of $\mathrm{H}_{2} \mathrm{O}$, DMSO, ethanol and acetone}

Thin films based on various chalcogenides are researched as sensors towards a range of gases, including ammonia, ${ }^{16}$ water $^{18,50}$ and volatile organic compounds (toluene, hexane, acetone, etc.). ${ }^{19,20}$ We took water, DMSO, ethanol and acetone as sample analytes for testing the sensing properties of the $\mathrm{Mo}_{2} \mathrm{~S}_{3}$ thin film. One can see from Fig. 9 that a positive response is registered for all four gases (resistance is increased), and the response depends on vapor concentration. The electrical resistance response of the $\mathrm{Mo}_{2} \mathrm{~S}_{3}$ sample to the change in humidity is shown in Fig. 9(a). The resistance of the sensing element increases sharply upon contact with water vapor and recovers to its original value once taken out of the chamber. The $\mathrm{Mo}_{2} \mathrm{~S}_{3}$ thin film sensor exhibited a quick response and recovery times of about $30 \mathrm{~s}$ for the maximum $\mathrm{H}_{2} \mathrm{O}$ concentration (defined as the time required to achieve $90 \%$ of the final equilibrium resistance value). This value is well comparable to those of recently reported $\mathrm{VS}_{2}$-based moisture sensors ${ }^{50}$ and exceeds the characteristics of detectors based on some other nanomaterials. ${ }^{51}$ One can see that there are distinct saturations for every $\mathrm{H}_{2} \mathrm{O}$ concentration, but there was no saturation for DMSO and for higher concentrations of acetone and ethanol (Fig. 9(b) and (c)). For DMSO the resistance increased linearly within the time range (Fig. 9(b)) and recovered very slowly in comparison with the rest of the analytes studied, with the time for complete recovery after contact with DMSO at a concentration of $110 \mathrm{ppm}$ being about $14000 \mathrm{~s}$ (see Fig. S7, ESI $\dagger$ ).

Therefore, the sensing behavior of the $\mathrm{Mo}_{2} \mathrm{~S}_{3}$ film is found to depend strongly on the chemical nature of gas molecules. But generally speaking, the changes in resistance constitute a complex phenomenon in chemiresistor studies and may be related to complicated combined mechanisms of physisorption, chemisorption, charge transfer, etc., ${ }^{19}$ and, moreover, capillary condensation may take place, thereby leading to mechanical separation of the conducting $\mathrm{Mo}_{2} \mathrm{~S}_{3}$ nanoparticles in the film and, as a result causing an increase of electrical resistance.

\section{Conclusions}

In summary, a combined computational and experimental study of molybdenum sulfide $\mathrm{Mo}_{2} \mathrm{~S}_{3}$ in its bulk and nanosized states is reported. For the first time, we show that this material with a quasi-layered structure may be exfoliated into sheet-like nanostructures, quite similar to the true layered materials, such as $\mathrm{MoS}_{2}$, h-BN or graphite. DFT calculations reveal the existence of a preferential exfoliation direction along the (101) plane, implying the breaking of both weak van der Waals bonds and stronger covalent Mo-S bonds between the "layers". Moreover, the cleaved few-layered structures may be stabilized by chemisorption of organic molecules, such as DMSO, which are often used in practice as solvents. This finding is verified by the experimental observation of sonication-induced colloidal dispersion of $\mathrm{Mo}_{2} \mathrm{~S}_{3}$ in a number of liquids. Stable colloids in DMSO, $\mathrm{NMP}$ or an ethanol/water mixture contain rectangular $\mathrm{Mo}_{2} \mathrm{~S}_{3}$ nanosheets, whose stabilization in the dispersed state may be in 
part due to the surface modification by solvent molecules. The gas sensing properties of a $\mathrm{Mo}_{2} \mathrm{~S}_{3}$ film deposited from the dispersions are investigated for the detection of water, ethanol, acetone, and DMSO. Overall, the presented theoretical study, synthetic method, and demonstration of solution processability of $\mathrm{Mo}_{2} \mathrm{~S}_{3}$ are all important steps for uncovering the potential of this material for various advanced applications, including energy storage, incorporation into composites, etc.

\section{Acknowledgements}

The work was supported by the Russian Foundation for Basic Research (17-03-00074). The authors would like to thank Dr I. A. Pyshnaya from the core facility of ICBFM SB RAS for DLS and z-potential measurements.

\section{References}

1 K. S. Novoselov, A. K. Geim, S. V. Morozov, D. Jiang, Y. Zhang, S. V. Dubonos, I. V. Grigorieva and A. A. Firsov, Science, 2004, 306, 666-669.

2 J. N. Coleman, M. Lotya, A. O’Neill, S. D. Bergin, P. J. King, U. Khan, K. Young, A. Gaucher, S. De, R. J. Smith, I. V. Shvets, S. K. Arora, G. Stanton, H. Y. Kim, K. Lee, G. T. Kim, G. S. Duesberg, T. Hallam, J. J. Boland, J. J. Wang, J. F. Donegan, J. C. Grunlan, G. Moriarty, A. Shmeliov, R. J. Nicholls, J. M. Perkins, E. M. Grieveson, K. Theuwissen, D. W. McComb, P. D. Nellist and V. Nicolosi, Science, 2011, 331, 568-571.

3 W. L. Yang, X. D. Zhang and Y. Xie, Nano Today, 2016, 11, 793-816.

4 V. Nicolosi, M. Chhowalla, M. G. Kanatzidis, M. S. Strano and J. N. Coleman, Science, 2013, 340, 1226419.

5 V. E. Fedorov, S. B. Artemkina, E. D. Grayfer, N. G. Naumov, Y. V. Mironov, A. I. Bulavchenko, V. I. Zaikovskii, I. V. Antonova, A. I. Komonov and M. V. Medvedev, J. Mater. Chem. C, 2014, 2, 5479-5486.

6 S. B. Artemkina, T. Y. Podlipskaya, A. I. Bulavchenko, A. I. Komonov, Y. V. Mironov and V. E. Fedorov, Colloids Surf., A, 2014, 461, 30-39.

7 M. N. Kozlova, Y. V. Mironov, E. D. Grayfer, A. I. Smolentsev, V. I. Zaikovskii, N. A. Nebogatikova, T. Y. Podlipskaya and V. E. Fedorov, Chem. - Eur. J., 2015, 21, 4639-4645.

8 P. A. Poltarak, S. B. Artemkina, A. I. Bulavchenko, T. Y. Podlipskaya and V. E. Fedorov, Russ. Chem. Bull., 2015, 64, 1850-1856.

9 E. D. Grayfer, M. N. Kozlova and V. E. Fedorov, Adv. Colloid Interface Sci., 2017, 245, 40-61.

10 D. Voiry, M. Salehi, R. Silva, T. Fujita, M. W. Chen, T. Asefa, V. B. Shenoy, G. Eda and M. Chhowalla, Nano Lett., 2013, 13, 6222-6227.

11 J. Xiao, D. W. Choi, L. Cosimbescu, P. Koech, J. Liu and J. P. Lemmon, Chem. Mater., 2010, 22, 4522-4524.

12 Y. L. Liang, R. J. Feng, S. Q. Yang, H. Ma, J. Liang and J. Chen, Adv. Mater., 2011, 23, 640-643.
13 R. J. Smith, P. J. King, M. Lotya, C. Wirtz, U. Khan, S. De, A. O’Neill, G. S. Duesberg, J. C. Grunlan, G. Moriarty, J. Chen, J. Z. Wang, A. I. Minett, V. Nicolosi and J. N. Coleman, Adv. Mater., 2011, 23, 3944-3948.

14 G. Eda, H. Yamaguchi, D. Voiry, T. Fujita, M. W. Chen and M. Chhowalla, Nano Lett., 2011, 11, 5111-5116.

15 V. Stengl and J. Henych, Nanoscale, 2013, 5, 3387-3394.

16 Y. Yao, Z. Lin, Z. Li, X. Song, K.-S. Moon and C.-P. Wong, J. Mater. Chem., 2012, 22, 13494-13499.

17 Y. Yao, L. Tolentino, Z. Yang, X. Song, W. Zhang, Y. Chen and C.-P. Wong, Adv. Funct. Mater., 2013, 23, 3577-3583.

18 S.-L. Zhang, H.-H. Choi, H.-Y. Yue and W.-C. Yang, Curr. Appl. Phys., 2014, 14, 264-268.

19 J. S. Kim, H. W. Yoo, H. O. Choi and H. T. Jung, Nano Lett., 2014, 14, 5941-5947.

20 X.-Q. Tian, L. Liu, X.-R. Wang, Y.-D. Wei, J. Gu, Y. Du and B. I. Yakobson, J. Mater. Chem. C, 2017, 5, 1463-1470.

21 F. Jellinek, Nature, 1961, 192, 1065-1066.

22 L. Brewer and R. H. Lamoreaux, Bull. Alloy Phase Diagrams, 1980, 1, 93-95.

23 I. G. Vasilyeva and R. E. Nikolaev, J. Alloys Compd., 2008, 452, 89-93.

24 G. T. Huang, W. H. Chao, J. K. Chang, H. D. Liao, D. C. Ling, F. Z. Chien and M. K. Wu, J. Supercond. Novel Magn., 2013, 26, 503-510.

25 S. Leidich, D. Buechele, R. Lauenstein, M. Kluenker and C. Lind, J. Solid State Chem., 2016, 242(part 2), 175-181.

26 R. Deblieck, G. A. Wiegers, K. D. Bronsema, D. Vandyck, G. Vantendeloo, J. Vanlanduyt and S. Amelinckx, Phys. Status Solidi A, 1983, 77, 249-261.

27 R. L. Fagerquist and R. D. Kirby, Phys. Rev. B: Condens. Matter Mater. Phys., 1988, 38, 3973-3985.

28 A. K. Rastogi, Philos. Mag. B, 1985, 52, 909-919.

29 A. I. Romanenko, F. S. Rakhmenkulov, I. N. Kuropyatnik, V. E. Fedorov and A. V. Mishchenko, Phys. Status Solidi A, 1984, 84, K165-K167.

30 W. J. Schutte, F. Disselborg and J. L. de Boer, Acta Crystallogr., Sect. B: Struct. Sci., 1993, 49, 787-794.

31 V. E. Fedorov, Transition metal chalcogenides. Quasionedimensional compounds, Nauka, Novosibirsk, 1988.

32 E. Shembel, R. Apostolova, I. Kirsanova and V. Tysyachny, J. Solid State Electrochem., 2008, 12, 1151-1157.

33 Y. Zhong, Y. Zhang, G. X. Zhang, R. Y. Li and X. L. Sun, Appl. Surf. Sci., 2012, 263, 410-415.

34 R. C. Che, N. Bai and L. M. Peng, Appl. Phys. Lett., 2003, 83, 3561-3563.

35 D. Z. Sun, W. H. Lu, D. Le, Q. Ma, M. Aminpour, M. A. Ortigoza, S. Bobek, J. Mann, J. Wyrick, T. S. Rahman and L. Bartels, Angew. Chem., Int. Ed., 2012, 51, 10284-10288.

36 V. Koroteev, A. Okotrub, Y. V. Shubin and L. Bulusheva, Key Eng. Mater., 2012, 508, 56-60.

37 R. K. Tiwari, J. Yang, M. Saeys and C. Joachim, Surf. Sci., 2008, 602, 2628-2633.

38 L. Debbichi, H. Kim, T. Björkman, O. Eriksson and S. Lebègue, Phys. Rev. B, 2016, 93, 245307. 
39 T. Bjorkman, A. Gulans, A. V. Krasheninnikov and R. M. Nieminen, Phys. Rev. Lett., 2012, 108, 235502.

40 J. M. Soler, E. Artacho, J. D. Gale, A. Garcia, J. Junquera, P. Ordejon and D. Sanchez-Portal, J. Phys.: Condens. Matter, 2002, 14, 2745-2779.

41 P. Monceau, M. Renard, J. Richard, M. C. Saintlager, H. Salva and Z. Z. Wang, Phys. Rev. B: Condens. Matter Mater. Phys., 1983, 28, 1646-1648.

42 E. Satheeshkumar, A. Bandyopadhyay, M. B. Sreedhara, S. K. Pati, C. N. R. Rao and M. Yoshimura, ChemNanoMat, 2017, 3, 172-177.

43 G. Guan, S. Zhang, S. Liu, Y. Cai, M. Low, C. P. Teng, I. Y. Phang, Y. Cheng, K. L. Duei, B. M. Srinivasan, Y. Zheng, Y.-W. Zhang and M.-Y. Han, J. Am. Chem. Soc., 2015, 137, 6152-6155.

44 P. Stadelmann, Electro Microscopy Software "JEMS", version:3.3526U2008. CIME-EPFL, Switzerland, 2008.
45 L. Muscuso, S. Cravanzola, F. Cesano, D. Scarano and A. Zecchina, J. Phys. Chem. C, 2015, 119, 3791-3801.

46 L. Guardia, J. I. Paredes, R. Rozada, S. Villar-Rodil, A. Martinez-Alonso and J. M. D. Tascon, RSC Adv., 2014, 4, 14115-14127.

47 A. Jawaid, D. Nepal, K. Park, M. Jespersen, A. Qualley, P. Mirau, L. F. Drummy and R. A. Vaia, Chem. Mater., 2016, 28, 337-348.

48 J. T. Han, J. I. Jang, H. Kim, J. Y. Hwang, H. K. Yoo, J. S. Woo, S. Choi, H. Y. Kim, H. J. Jeong, S. Y. Jeong, K.-J. Baeg, K. Cho and G.-W. Lee, Sci. Rep., 2014, 4, 5133.

49 R. Bhandavat, L. David and G. Singh, J. Phys. Chem. Lett., 2012, 3, 1523-1530.

50 J. Feng, L. L. Peng, C. Z. Wu, X. Sun, S. L. Hu, C. W. Lin, J. Dai, J. L. Yang and Y. Xie, Adv. Mater., 2012, 24, 1969-1974.

51 Q. Kuang, C. S. Lao, Z. L. Wang, Z. X. Xie and L. S. Zheng, J. Am. Chem. Soc., 2007, 129, 6070-6071. 